УДК 911(470.341)

ОЦЕНКА ПРИРОДНО-ЭКОЛОГИЧЕСКОЙ И СОЦИАЛЬНОЙ КОМФОРТНОСТИ ПРОЖИВАНИЯ НАСЕЛЕНИЯ В ГОРОДСКОМ ОКРУГЕ ГОРОДА ДЗЕРЖИНСКА НИЖЕГОРОДСКОЙ ОБЛАСТИ

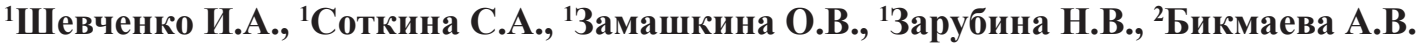

${ }^{l}$ ФГБОУ ВО «Нижегородский государственный педагогический университет имени К. Минина», Нижний Новгород, е-mail: irina-dzr52@mail.ru;

${ }^{2}$ ФГБОУ ВО «Российская академия народного хозяйства и государственной службы при Президенте РФ», Дзержсинский филиал, Дзержинск, e-mail: big-dzrnn@mail.ru

В статье рассмотрена актуальная проблема создания комфортной среды обитания населения Нижегородской области, в частности городского округа г. Дзержинска. Оценка комфортности проживания населения на городском уровне представляет большой научный интерес. В ходе проведенной работы предложен алгоритм оценки комфортности проживания населения в г. Дзержинске. Создана тематическая карта определяющих социальных условий городской среды, на основе которых разработана и составлена интегральная карта социальной комфортности проживания населения на территории г. Дзержинска, что позволило выделить территории с разной степенью комфортности. Был определен уровень климатической комфортности территории, определено, что карстовые явления имеют удовлетворительную степень распространения, при которой жителям обеспечена безопасность и удовлетворительная среда проживания. К благоприятным показателям города отнесены: географическое положение, удобная транспортная развязка, благоприятный климат, наличие водных ресурсов. К неблагоприятным отнесена высокая закарстованность территории, сосредоточение опасного химического производства, выбросы которого дают загрязнение атмосферы, гидросферы и педосферы. Большая часть г. Дзержинска находится в зоне распространения довольно хорошо организованной системы социального обслуживания, которая удовлетворяет потребности населения. Рассчитан средний показатель комфортности проживания в городе. Интегральная оценка комфортности проживания населения городского округа г. Дзержинска становится необходимой, поскольку в данном масштабе можно провести анализ природно-экологических и социальных условий данной территории и сформировать городские культурные ландшафты, отвечающие требованиям, предъявляемым населением к территории проживания. Исследование имеет ярко выраженное практическое значение и может быть использовано администрацией г. Дзержинска в вопросах изучения и написания рекомендаций по улучшению состояния городской среды и экологической комфортности проживания населения. Представленная в работе карта объективно отражает сложившуюся эколого-геохимическую ситуацию.

Ключевые слова: образ жизни, население, уровни комфортности, природно-экологическая комфортность, социальная комфортность, оценка комфортности

\title{
ASSESSMENT OF THE NATURAL-ECOLOGICALAND SOCIAL COMFORT OF LIVING IN THE CITY DISTRICT OF DZERZHINSK, NIZHNY NOVGOROD REGION \\ ${ }^{1}$ Shevchenko I.A., ${ }^{1}$ Sotkina S.A., ${ }^{1}$ Zamashkina O.V., ${ }^{1}$ Zarubina N.V., ${ }^{2}$ Bikmaeva A.V. ${ }^{1}$ Minin Nizhny Novgorod State Pedagogical University, Nizhny Novgorod, e-mail: irina-dzr52@mail.ru; ${ }^{2}$ The Russian Presidential Academy of National Economy and Public Administration, Dzerzhinsk branch, Dzerzhinsk,e-mail: big-dzrnn@mail.ru
}

This article discusses the actual problem of creating a comfortable environment for the population of the Nizhny Novgorod region, in particular, the city district of Dzerzhinsk. Assessing the comfort of living at the urban level is of great scientific interest. In the course of this work, an algorithm for evaluating the comfort of living in the city of Dzerzhinsk is proposed. A thematic map was created that defines the social conditions of the urban environment, on the basis of which an integrated map of social comfort of living in the city was developed and compiled. Dzerzhinsk, which made it possible to allocate territories with different degrees of comfort. The level of climatic comfort of the territory was determined, it was determined that karst phenomena have a satisfactory degree of distribution, in which the residents are provided with security and a satisfactory living environment. The city's favorable indicators include its geographical location, convenient transportation, favorable climate, and availability of water resources. The most unfavorable are the high density of the territory, the concentration of dangerous chemical production, whose emissions cause pollution of the atmosphere, hydrosphere and pedosphere. Most of Dzerzhinsk is located in the distribution zone of a fairly well-organized social service system that meets the needs of the population. The average indicator of comfort of living in the city is calculated. An integral assessment of the comfort of living of the population of the city district of Dzerzhinsk becomes necessary, since at this scale it is possible to analyze the natural-ecological and social conditions of this territory and create urban cultural landscapes that meet the requirements of the population to the territory of residence. The study has a pronounced practical significance and can be used by the administration of Dzerzhinsk in the study and writing recommendations for improving the state of the urban environment and environmental comfort of the population. The maps presented in this paper objectively reflect the current ecological and geochemical situation.

Keywords: lifestyle, population, comfort levels, natural and environmental comfort, social comfort, assessment of comfort

Нижегородская область располагает огромным как природно-ресурсным, так и социально-экономическим потенциалом для своего дальнейшего развития и созда- ния благоприятной и комфортной среды обитания, у которой есть все необходимое большая территория, историческое и культурное наследие. Городской округ города 
Дзержинск Нижегородской области входит в список одних из самых загрязненных городов России благодаря сосредоточению на небольшой территории серьёзного химического производства. По результатам многочисленных исследований можно сказать, что эколого-геохимическая ситуация в Дзержинске не хуже, чем в ближайших районах Нижнего Новгорода [1]. В связи с этим данное исследование имеет практическую значимость, так как Дзержинск считается не только грязным, но и красивым городом Нижегородской области, со своей историей и культурой. Более детальное изучение и ранжирование загрязнения Дзержинска выделяет восточную промышленную зону, а сам город, как правило, имеет опасное или допустимое загрязнение по многим показателям. Поэтому необходимо уделять данной территории повышенное внимание и изучать проблему Дзержинска более детально.

Как отмечает Б.И. Кочуров, совокупность различных условий, наиболее благоприятных для жизни населения регионов, формирует природно-экологическую комфортность, а благоприятных для хозяйственной деятельности населения социально-экономическую комфортность проживания. При рассмотрении природно-экологической комфортности учитывается совокупность таких условий, которые удовлетворяют основные физиологические потребности проживающего на исследуемой территории населения. Изучение социально-экономической комфортности предполагает анализ различных социальных и экономических факторов, оказывающих влияние на жизнедеятельность населения [2].

Цель исследования - оценка комфортности проживания населения в городском округе г. Дзержинска как интегрального геоэкологического показателя, формирование позитивных представлений о г. Дзержинске в географическом и экологическом аспектах. Дзержинск - второй по численности населения и промышленному потенциалу город Нижегородской области. На 01.01.2020 г. Дзержинск относится к городам первой группы химической опасности, являясь крупным центром химической промышленности России, поэтому в числе основных задач данной работы было проведение интегральной оценки природно-экологической и социальной комфортности проживания населения городского округа г. Дзержинска.

\section{Материалы и методы исследования}

В процессе исследования нами были рассмотрены современные подходыпо оценке комфортности проживания населения городского округа Дзержинск Нижегородской области. Теоретико-методологическую основу исследования составили работы Н.Ф. Реймерса, Ф.Н. Милькова, Г.М. Лаппо, Д.Л. Арманда, Б.И. Кочурова, С.А. Соткиной, И.В. Зорина, В.А. Квартальнова, а также нормативные документы Администрации городского округа г. Дзержинска. При проведении данного исследования использовались такие методы, как анализ научной и краеведческой литературы, картографический, статистических данных, сравнительно-географический и сравнительно-исторический методы. С целью определения уровня климатической комфортности территории была взята схема экспертных оценок К. Саати, где указаны основные показатели, характеризующие уровень климатической комфортности территории [3].

Ультрафиолетовая недостаточность на территории характеризуется периодом в 20-25 дней. Число дней с суровыми погодными условиями (зима) исчисляется с 130-145 дней, оттого продолжительность безморозного периода составляет более 110 дней. Отсутствует продолжительность полярного дня и полярной ночи. В целом климат Дзержинска умеренно континентальный со всеми характерными для него чертами. Продолжительность благоприятных погод на территории также характеризуется числом более 40 дней. Следуя схеме экспертных оценок Саати, территорию г. Дзержинска можно определить, как комфортную для жизни населения. Только показатель, характеризующий ультрафиолетовую недостаточность, можно характеризовать как прекомфортные условия.

Развитие карстово-суффозионного процесса на территории происходило в более ранние этапы геологической истории и продолжается до настоящего времени. На территории городского округа Дзержинск развивается преимущественно карбонатно-сульфатный и гипсовый карст. Карст остается серьезной экологической проблемой для города. ОАО «Противокарстовая и береговая защита» проводит многолетние наблюдения за карстово- суффозионными процессами в районе Дзержинска на площади около 230 кв. км, где за последние 55 лет отмечено 260 новых карстовых провалов. Были сделаны подсчеты степени рас- 
пространения карста и выявлено, что на вторую категорию опасности приходится лишь $3,9 \%$ от общей территории г. Дзержинска, к 3 категории опасности относится 6,08\%, к четвертой 16,5\%, а к пятой 17,3\% т.е. общая площадь города, подверженная карстам, составляет 43,78\%. Причем большая часть города или вовсе не подвержена карсту, или имеет лишь 5 класс опасности. Что позволяет сделать вывод о том, что на сегодняшний день, с точки зрения комфортности проживания населения в г. Дзержинске, карстовые явления не носят катастрофический или дискомфортный характер. На сегодняшний день можно сделать выводы о том, что карстовые явления имеют удовлетворительную степень распространения, при которой жителям обеспечена безопасность и удовлетворительная среда проживания, при наличии соответствующего и своевременного карстологического мониторинга.

В течение года наблюдается от 144 до 255 дней с неблагоприятными для города метеорологическими условиями, способствующими росту загрязнения воздуха в жилых кварталах. В эти периоды на предприятиях выполняется комплекс мер по снижению выбросов вредных веществ. При этом имеются определенные различия в состоянии загрязнения воздушного бассейна отдельных районов города: наиболее загрязненными являются западные районы. Результаты наблюдений свидетельствуют о том, что уровень загрязнения воздушного бассейна в городе в последний год соответствует среднему значению по России. Город остается, однако, одним из наиболее загрязненных городов Нижегородской области. Дзержинск характеризуется высоким уровнем загрязнения атмосферы и, наряду с г. Н. Новгородом, вошёл в число наиболее неблагополучных в экологическом отношении населенных пунктов.

Одним из наиболее важных факторов является обеспечение его доброкачественной питьевой водой: по состоянию на 2019 г. из 78 источников централизованного водоснабжения 19 не соответствуют требованиям СанПиН 2.1.4.027-95. В последнее время наблюдается стойкая тенденция ухудшения качества воды открытых водоемов в зонах рекреации по бактериологическим показателям, поскольку до настоящего времени не реализован план мероприятий по благоустройству и оборудованию городских пляжей, что оказывает отрицательное влияние на состояние водоёмов в весенне-летний сезон отдыха.
В снежном покрове приоритетными загрязняющими веществами г. Дзержинска и его восточной промышленной зоны в зимний период обследования 2019 г. из числа тяжелых металлов по сумме растворимой и нерастворимой части являются медь, олово, свинец, молибден, ванадий. Наиболее высокое загрязнение снежного покрова наблюдается на территории пос. Петряевка, расположенного в зоне влияния восточной группы предприятий и для территории западных районов пос. Свердлова, находящихся под прямым влиянием выбросов западной группы предприятий. По данным обследования по суммарному индексу загрязнения почв тяжелыми металлами вся обследуемая территория г. Дзержинска относится к категории допустимого загрязнения $(\mathrm{Z} \phi=6,8)$. Однако на территории пос. Петряевка, д. Колодкино и П. Игумново имеются точки, в которых данный показатель загрязнения достигает уровня умеренно опасного загрязнения почв, а в единственной точке (п. Игумново, ул. П. Морозова, 31) - уровня опасного загрязнения. Оценивая географические показатели Дзержинска, можно сделать следующие выводы, что к благоприятным показателям следует отнести географическое положение, удобную транспортную развязку, благоприятный климат, наличие водных ресурсов. К неблагоприятным - высокую закарстованность территории, сосредоточение на небольшой территории опасного химического производства. Как следствие, выбросы дают загрязнение атмосферы, гидросферы и педосферы [4].

На комфортность проживания населения огромную роль оказывают зеленые насаждения. На цели озеленения в 2019 г. было израсходовано 24378,79 тыс. руб. из бюджета города, в том числе омоложение 379 деревьев, омоложение живых изгородей из кустарника - 130,0 м, снос 618 аварийных деревьев. Осуществлено текущее содержание зеленых насаждений города на площади 841,28 тыс. кв. м. В качестве компенсационной стоимости уничтожаемых зеленых насаждений в бюджет города поступило 8121,67 тыс. руб. В качестве компенсационного озеленения было посажено 5339 деревьев (за счет привлеченных средств). Важно отметить, что зеленые насаждения также важны для очищения городской среды. Таким образом, озеленение территории напрямую влияет на комфортность проживания населения. В настоящее время в соответствии с Генеральным пла- 
ном городского округа Дзержинск городские озеленения территории общего пользования занимают территорию 150 га [5].

\section{Результаты исследования и их обсуждение}

В результате проведения интегральной оценки городского округа г. Дзержинска Нижегородской области были получены следующие результаты. Для расчета комплекса экологических показателей, был проведен расчет площадей (га) жилой застройки, промышленной застройки и фактически озелененных территорий по карте г. Дзержинска. Полученные значения представлены в таблице. падный: 37,6 \% составляет жилая застройка и $62,4 \%$ территории занимают фактически озелененные территории [6].

Самые большие территории, фактически озелененные территории земель располагаются в Западном и Прибрежном микрорайонах. Самая маленькая по площади территория фактически озелененных территорий земель приходится на Центральный микрорайон. Восточный микрорайон характеризуется наличием большой территории промышленной застройки. В Северном микрорайоне также большую часть территории занимает промышленная застройка.

Для расчета степени озеленения территории общего пользования (Q) г. Дзержинска

Расчет комплекса экологических показателей

\begin{tabular}{|l|c|c|c|c|}
\hline \multicolumn{1}{|c|}{ Микрорайон } & $\begin{array}{c}\text { Жилая застройка, } \\
\text { га }\end{array}$ & $\begin{array}{c}\text { Промышленная } \\
\text { застройка, га }\end{array}$ & $\begin{array}{c}\text { Фактически озелененные } \\
\text { территории, га }\end{array}$ & Всего, га \\
\hline Прибрежный & 239,76 & 31,68 & 298,8 & 570,24 \\
\hline Восточный & 177,12 & 70,56 & 97,92 & 345,6 \\
\hline Центральный & 567,36 & 7,2 & 79,2 & 653,76 \\
\hline Северный & 180 & 60,48 & 185,76 & 426,24 \\
\hline Северо-Западный & 302,4 & 145,44 & 169,92 & 617,76 \\
\hline Юго-Западный & 453,6 & 24,48 & 119,52 & 597,6 \\
\hline Западный & 217,44 & - & 302,4 & 577,44 \\
\hline Общая площадь & 2137,68 & 339,84 & 1253,52 & 3731,04 \\
\hline
\end{tabular}

Таким образом, общая площадь города составляет 3731,04 га. Рассмотрим каждый микрорайон по отдельности. Прибрежный район: $42,04 \%$ составляет жилая застройка, 5,6\% приходится на промышленную застройку и $52,36 \%$ остается на фактически озелененные территории. Восточный район: $51,25 \%$ составляет жилая застройка, $20,4 \%$ территории занимает промышленная застройка, $28,35 \%$ приходится на фактически озелененные территории. Центральный район: $86,8 \%$ занимает жилая застройка, $1,1 \%$ составляет промышленная застройка и $12,1 \%$ территории занимают фактически озелененные территории. Северный район: $42,2 \%$ территории занимает жилая застройка, $14,19 \%$ составляет промышленная застройка, 43,6\% приходится на фактически озелененные территории. Северо-западный: $49 \%$ территории занимает жилая застройка, $24 \%$ занимает промышленная застройка и $27 \%$ приходится на фактически озелененные территории. Юго-западный: $75,9 \%$ составляет жилая застройка, $4,1 \%$ занимает промышленная застройка и $20 \%$ приходится на рекреационные земли. За- в соответствии с Законом Нижегородской области [7] нам нужны следующие показатели: Sоб. - площадь озелененных территорий общего пользования в г. Дзержинск; T - фактическая численность населения в г. Дзержинске на данный период.

Расчет: $\mathrm{Q}=$ Sоб/T; $\mathrm{Q}=150,0 / 237668=$ $=0,00063113$ га, т.е. $\mathrm{Q}=6,3113$ кв. м. Таким образом, с численностью населения г. Дзержинска в 237668 чел. территория не отвечает нормам в соответствии с Законом Нижегородской области, норматив озелененных территорий общего пользования на 1 человека почти в 2,5 раза меньше заявленного минимума.

Для расчета степени озеленения фактически озелененных территорий (F) г. Дзержинска в соответствии с Законом Нижегородской области нам нужны следующие показатели: Общая площадь фактически озелененной территории (Sоз.) и общая Площадь территории (S).

Расчет: $\mathrm{F}=$ Sоз. $* 100 \% / \mathrm{S} ; \quad \mathrm{F}=1253,5$ $2 * 100 \% / 3731,04=33,6 \%$, т.e. $\mathrm{F}=33,6 \%$. Таким образом, с общей площадью фактически озелененных территорий равной 
1253,52 га, т.е. 33,6\% от общей площади города, территория не отвечает нормам в соответствии с Законом Нижегородской области, норматив фактически озелененных территорий общего пользования должен составлять не менее $70 \%$ от общей площади территории [7]. Результатом этих расчетов можно считать вывод о том, что г. Дзержинск является дискомфортным в плане обеспеченности озелененными территориями, так как они не удовлетворяют запрос населения и общественные нормы, регламентируемые в соответствии с Законом Нижегородской области.

\section{Выводы}

Таким образом, в ходе проведенной работы предложен алгоритм оценки комфортности проживания населения в г. Дзержинске. При анализе обеспеченности объектами социальной инфраструктуры получены следующие результаты: самой комфортной территорией г. Дзержинска с точки зрения обеспечения объектами социальной инфраструктуры является Центральный микрорайон. Далее уровень комфортности населения падает до прекомфортных показателей, в связи с небольшим отдалением от главнейших

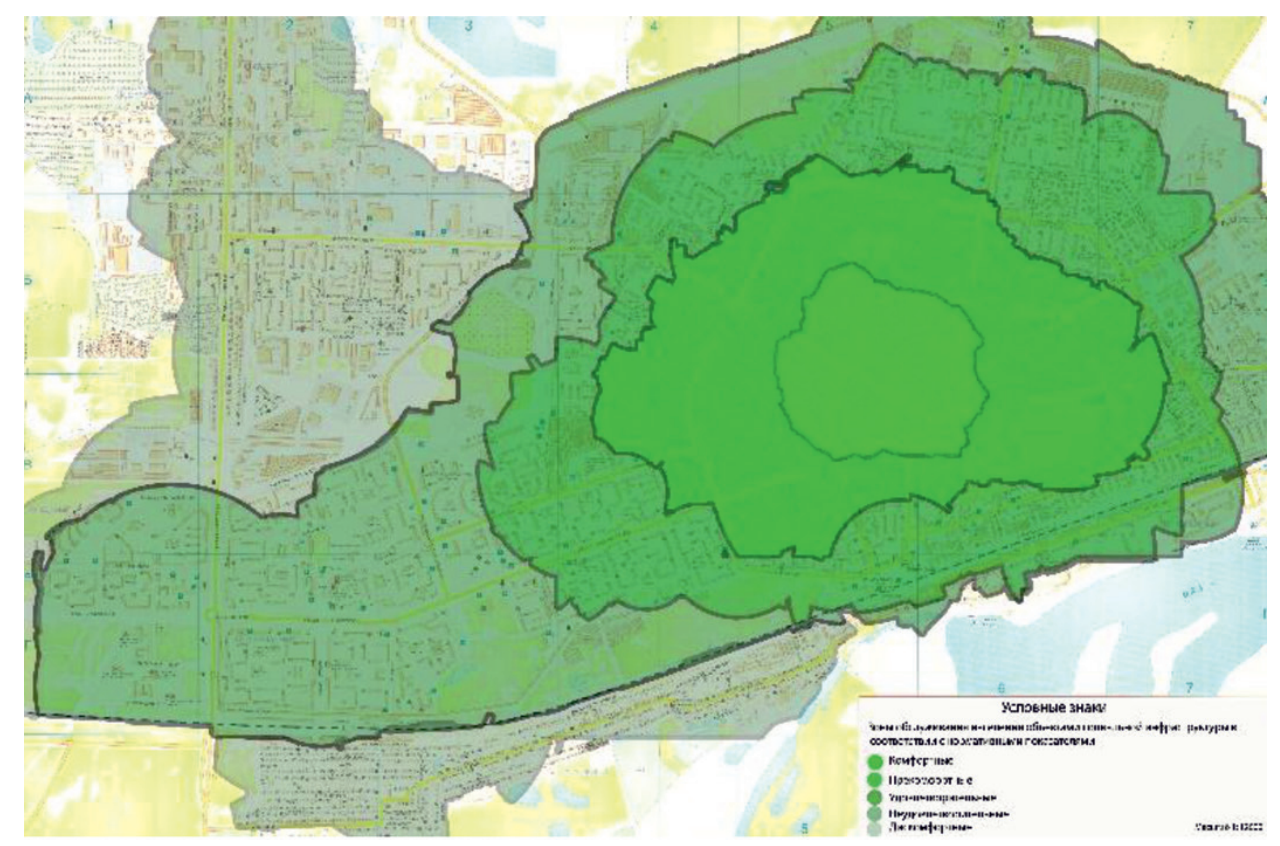

Уровень социильной комфортности проживания населения в г. Дзержинске

Для дальнейшей оценки социальной комфортности проживания населения [8] нами выполнялось наложение карт по радиусам обслуживания и обеспеченности населения объектами социальной инфраструктуры и получена оценочная карта социальной комфортности проживания населения в г. Дзержинске. Для оценки социальной комфортности проживания населения нами предложено выделить участки (жилые массивы), обеспеченные объектами социальной инфраструктуры, и зоны с учетом радиуса обслуживания населения в соответствии нормативным значениям. Для нашего города такая оценка производилась впервые (рисунок, условные знаки: комфортная, прекомфортная, удовлетворительная, неудовлетворительная, дискомфортная). объектов социальной инфраструктуры. Далее идет понижение до удовлетворительных условий проживания населения, причем понижение обеспеченности территории объектами социальной инфраструктуры имеет тенденцию радиального характера, т.е. чем дальше от центра, тем менее комфортны условия. Самым дискомфортными районами проживания населения являются СевероЗападный и Юго-Западный микрорайоны, включая территорию частной застройки Пушкино. В целом большая часть г. Дзержинска находится в зоне распространения довольно хорошо организованной системы социального обслуживания, на большей части территории города довольно хорошо развита инфраструктура, которая удовлетворяет потребности населения. Лишь толь- 
ко отдаленные от центра территории имеют затруднения в обеспеченности основными объектами социальной инфраструктуры. Используя данные, можно рассчитать средний показатель комфортности проживания населения в г. Дзержинске, которые равен 2,8 , что соответствует удовлетворительному уровню. Исследование имеет ярко выраженное практическое значение и может быть использовано администрацией г. Дзержинска в вопросах изучения и написания рекомендаций по улучшению состояния городской среды и экологической комфортности проживания населения. Интегральная оценка комфортности проживания населения городского округа г. Дзержинск становится необходимой, поскольку в данном масштабе возможен анализ природноэкологических и социальных условий данной территории и формирование городских культурных ландшафтов.

\section{Список литературы / References}

1. Соткина С.А., Кривдина И.Ю., Никитина О.А. Комфортность проживания населения на территории городских агломераций с точки зрения оценки эколого-геохимической ситуации (на примере Нижегородской агломерации) // Современные проблемы науки и образования. 2014. № 6. [Электронный ресурс]. URL: http://science-education.ru/ru/article/ view?id=17086 (дата обращения: 27.08.2020).

Sotkina S.A., Krivdina I.Yu., Nikitina O.A. The standard of living in the territory of urban agglomerations from the point of view of assessing the ecological and geochemical conditions (for example Nizhny Novgorod) // Successes of modern natural science. 2014. № 6. [Electronic resource]. URL: http://science-education.ru/ $\mathrm{ru} /$ article/view?id=17086 (дата обращения: 17.08.2020).

2. Кочуров Б.И., Жулина М.А. Оценка качества жизни населения: определения, подходы и критерии // Проблемы региональной экологии. 2005. № 4. С. 89-93.

Kochurov B.I., Zhulina M.A. Assessment of the quality of life of the population: definitions, approaches and criteria // Problemy regional'noy ekologii. 2005. № 4. P. 89-93 (in Russian).

3. Бабаева А.В., Крашенинников А.А. Антропологическое измерение пространства современного города // Вестник Мининского университета. 2019. Т. 7. № 2 (27). [Электронный pecypc]. URL: https://vestnik.mininuniver.ru/ jour/article/view/27 (дата обращения: 17.08.2020). DOI: 10.26795/2307-1281-2019-7-2-14.
Babaeva A.V., Krasheninnikov A.A. Anthropological measurement of modern city space // Vestnik of Minin University. 2019. Vol. 7. № 2 (27). [Electronic resource]. URL: https:// vestnik.mininuniver.ru/jour/article/view/27 (date of access: 07.05.2020) (in Russian).

4. Соткина С.А., Бадьина О.Н., Шевченко И.А., Бикмаева А.В. Экологическое состояние города Дзержинска по степени загрязнения почвенного покрова тяжелыми металлами // Успехи современного естествознания. 2017. № 6. C. 96-101.

Sotkina S.A., Shevchenko I.A., Badina O.N., Bikmaeva A.V. Ecological status of the city of Dzerzhinsk by the degree of contamination of the soil cover with heavy metals // Advances in current natural sciences. 2017. № 6. P. 96-101 (in Russian).

5. Решение Городской Думы г. Дзержинска Нижегородской области от 30 января 2020 г. № 830 «Об утверждении Стратегии социально-экономического развития городского округа город Дзержинск до 2030 года». [Электронный pecypc]. URL: https://internet.garant.ru/\#/document/73564662/ entry/0 (дата обращения: 17.08.2020).

Decision Of the city Duma of Dzerzhinsk of the Nizhny Novgorod region of January 30, 2020 № 830 «on approval of The strategy of socio-economic development of the city district of Dzerzhinsk until 2030». [Electronic resource]. URL: https://internet.garant.ru/\#/document/73564662/ entry/0 (date of access: 17.08.2020) (in Russian).

6. Асташин А.Е., Самойлов А.В., Пашкин М.Н., Пудеева О.Н., Фомина А.И., Власов А.В. Ландшафтное районирование территории городского округа Дзержинск Нижегородской области // Естественные и технические науки. 2019. № 1 (127). C. 96-100.

Astashin A.E., Samoilov A.V., Pashkin M.N., Pudeeva O.N., Fomina A.I., Vlasov A.V. Landscape zoning of territory of city district Dzerzhinsk of Nizhny Novgorod region // Yestestvennyye i tekhnicheskiye nauki. 2019. № 1(127). P. 96100 (in Russian).

7. Закон Нижегородской области от 07.09.2007 (с изменениями на 30 октября 2019 года) № 110-3 «Об охране озелененных территорий Нижегородской области». [Электронный ресурc]. URL: http://base.garant.ru/8536330 (дата обращения: 17.08.2020).

Law of the Nizhny Novgorod region of 07.09.2007 (as amended on October 30, 2019) No. 110-Z «on the protection of green areas of the Nizhny Novgorod region». [Electronic resource]. URL: http://base.garant.ru/8536330 (date of access: 17.08.2020) (in Russian).

8. Скворцова М.А., Лещайкина М.В. Разработка методики оценки уровня социальной комфортности проживания населения в регионе // Вестник Волжского университета имени В.Н. Татищева. 2010. № 19. С. 141-145.

Skvortsova M.A., Leshchaykina M.V. Development of methods for assessing the level of social comfort of living in the region // Vestnik Volzhskogo universiteta imeni V.N. Tatishcheva. 2010. № 19. P. 141-145 (in Russian). 